05

\title{
Изменения диэлектрических и механических свойств сферопластика, содержащего металлизированные стеклянные микросферы, вызванные деформацией сжатия
}

\author{
() Д.Н. Садовничий, Ю.М. Милехин, С.А. Малинин, Т.Л. Вихорнова, А.Н. Осавчук, В.П. Мельников, \\ К.Ю. Шереметьев, Н.В. Перцев
}

Федеральный центр двойных технологий „Союз“, 140090 Дзержинский, Россия

e-mail: soyuz@fcdt.ru

Поступило в Редакцию 3 декабря 2019 г.

В окончательной редакции 3 декабря 2019 г.

Принято к публикации 28 января 2020 г.

\begin{abstract}
Представлены экспериментальные результаты изменений диэлектрических и механических характеристик сферопластика на основе кремнийорганического эластомера и металлизированных стеклянных микросфер, вызванных статическим и ударным сжатием. Установлено наличие двух областей частотной дисперсии диэлектрической проницаемости, связанных с наличием металлического покрытия микросфер. Обнаружено, что при относительной деформации сжатия не менее 70\% наблюдается резкое снижение как низкочастотной, так и высокочастотной дисперсии комплексной диэлектрической проницаемости. Обсуждены возможные причины обнаруженного изменения комплексной диэлектрической проницаемости.
\end{abstract}

Ключевые слова: сферопластик, микросферы, диэлектрические характеристики, механические характеристики.

DOI: 10.21883/JTF.2020.07.49445.384-19

\section{Введение}

Сферопластики или синтактические пены представляют собой гетерогенные системы, состоящие из распределенных в полимерном связующем полых микросфер. Сферопластики находят широкое применение в авиационной, морской и космической технике благодаря низким плотностям, диэлектрическим проницаемостям, теплопроводностям и широким возможностям регулирования механических характеристик [1-3]. В настоящее время подробно изучено изменение механических свойств синтактических пен при статическом растяжении, сжатии, изгибе, а также ударно-волновых и динамических нагрузках [4-9]. Показано, что механические свойства сферопластиков зависят от химического состава и объемных долей микросфер, отношения толщины стенки микросферы к ее радиусу, типа используемого полимерного связующего и особенностей формирования адгезионной связи у поверхности микросферы. С целью придания сферопластикам свойств экранирования электромагнитных полей создаются микросферы с нанесенными на их поверхность металлами, что перспективно для применения в электронной технике $[10,11]$. Очевидно, что диэлектрические свойства сферопластиков, содержащих микросферы с толщиной металлического покрытия больше толщины скин-слоя, во многом должны соответствовать закономерностям, полученным для полимерных композитов, содержащих металлические частицы $[12,13]$. Так, помимо свойств полимерной матрицы, на диэлектрические свойства сферопластиков с металлизированными сферами должны оказывать влияние объемная доля и свойства металла, нанесенного на поверхность микросфер, перенос носителей заряда между металлизированными микросферами, а также геометрические факторы $[14,15]$. В условиях воздействия наносекундного потока релятивистских электронов недавно было обнаружено формирование нитевидных структур (нановискеров) при разрушении микросфер в сферопластике [16]. Разрушение металлизированных микросфер должно сказываться и на диэлектрических характеристиках, однако особенности изменения диэлектрических свойств сферопластиков при разрушении металлизированных микросфер до настоящего времени отсутствуют.

В настоящей работе в частотном диапазоне от $40 \mathrm{~Hz}$ до $1 \mathrm{GHz}$ экспериментально изучено изменение диэлектрических характеристик, а также механических свойств сферопластиков, вызванных статическим и ударным сжатием.

\section{1. Экспериментальная часть}

В экспериментах использовали плоские образцы сферопластика, состоящего из кремнийорганического эластомера, и стеклянных модифицированных вольфрамом микросфер диаметром 20-100 $\mu \mathrm{m}$. Массовая доля микросфер составляла $28 \%$. Толщина стеклянной стенки микросфер 2-2.5 $\mu \mathrm{m}$, а толщина вольфрамового покрытия $0.1-0.15 \mu \mathrm{m}$. Плотность сферопластика $710 \mathrm{~kg} / \mathrm{m}^{3}$. Температура испытаний комнатная. Нанесение металли- 
ческого слоя на микросферы выполнено путем химического осаждения из газовой фазы.

В качестве меры сжатия образца принималась усредненная по его объему осевая деформация пластины

$$
\varepsilon_{z}=\frac{u(t)-u_{0}}{h_{0}}
$$

где $u(t)$ - перемещение верхней поверхности нагружаемого образца, $u_{0}$ - перемещение нижней поверхности образца $\left(u_{0}=0\right.$ при абсолютно жестком основании), $h_{0}$ - начальная толщина образца.

Для оценки жесткости материала использовался эффективный модуль упругости $E$, связывающий осевые напряжения $\sigma_{z}$ с осевой деформацией $\varepsilon_{z}$ согласно $\sigma_{z}=E \varepsilon_{z}$. При этом

$$
\sigma_{z}=\frac{P}{S_{0}}
$$

где $P-$ сила, приложенная к образцу, $S_{0}-$ начальная площадь поверхности нагружения.

Статическое сжатие проводили на универсальной испытательной машине Instron 5585 со скоростью перемещения подвижной траверсы $5 \mathrm{~mm} / \mathrm{min}$. Степень сжатия пластины фиксировали по записи диаграммы деформирования пластины сферопластика.

Ударная нагрузка создавалась на копровой установке путем сброса с заданной высоты стального ударника на пластину сферопластика. Степень сжатия пластины фиксировали с использованием скоростной видеокамеры Video Scan „VideoSprint“. Величину достигнутого напряжения рассчитывали с использованием показаний датчика перегрузки, установленного на верхнем торце ударника. Подробно методика проведения экспериментов по ударному нагружению представлена в работе [17].

Для статического и ударного нагружений использовали образцы в форме пластин размерами $50 \times 50 \mathrm{~mm}$, толщиной $\sim 8-8.5 \mathrm{~mm}$. После нагружения из центральной части пластин сферопластика в направлении приложения силы вырезали цилиндрические образцы диаметром $5 \mathrm{~mm}$ и высотой 8-8.5 mm. Определение механических характеристик проводили на универсальной испытательной машине Instron 5565 при скорости перемещения подвижной траверсы $5 \mathrm{~mm} / \mathrm{min}$. Эффективный модуль упругости $(E)$ определяли на начальном участке диаграммы сжатия (до 10\%). Результаты измерений модуля упругости и прочности на сжатие $\left(\sigma_{z}\right)$ усредняли по результатам испытаний не менее 5 цилиндрических образцов.

Комплексную диэлектрическую проницаемость определяли на образцах толщиной 2-2.5 mm, вырезанных из центральной части исходных и подвергавшихся нагружению пластин сферопластика. Для частот электрического поля $(f)$ от 1 до $1264 \mathrm{MHz}$ измерения выполнены методом коаксиальной линии с использованием диэлектрического спектрометра Novocontrol BDS-70 и радиочастотной ячейки BDS2200 с измерительными электродами BDS2214 (диаметр измерительного электрода $d=10 \mathrm{~mm}$ ). Амплитуда подаваемого на образец синусоидального электрического поля $0.5 \mathrm{~V}$. Измеряли емкость $(C)$ и тангенс угла диэлектрических потерь $(\operatorname{tg} \delta)$. В области частот электрического поля от 40 до $5 \cdot 10^{6} \mathrm{~Hz}$ использовали автобалансируемый мост Agilent HР4294А. Амплитуда подаваемого синусоидального напряжения составляла 1 V. Измерения амплитуды и сдвига фаз протекающего через образец тока выполняли по двухэлектродной схеме. Диаметр измерительного электрода составлял $10 \mathrm{~mm}$. При расчете емкости образца учитывали краевую емкость и емкость измерительной ячейки относительно земли согласно ГОСТ 22372-77.

Измерения диэлектрической проницаемости в каждом из диапазонов частот проведены при не менее чем 80 значениях частот электрического поля $f$ с равномерным логарифмическим шагом. Рассчитывали действительную $\varepsilon^{\prime}=4 C h /\left(\varepsilon_{0} \pi d^{2}\right)$ и мнимую $\varepsilon^{\prime \prime}=\varepsilon^{\prime} \operatorname{tg} \delta$ части комплексной относительной диэлектрической проницаемости $\left(\varepsilon_{0}\right.$ - электрическая постоянная). Измерения проводили при комнатной температуре.

Для изучения структурных изменений в сферопластике использовали растровый электронный микроскоп JSM-6490.

\section{2. Результаты экспериментов и их анализ}

\section{1. Статическое нагружение}

На рис. 1 представлена типовая диаграмма сжатия исходной пластины сферопластика на установке Instron 5585 при скорости перемещения подвижной траверсы $5 \mathrm{~mm} / \mathrm{min}$. Видно, что до $\sim 10 \%$ деформирования наблюдается практически линейная зависимость относительной деформации $\left(\varepsilon_{z}\right)$ от напряжения $\left(\sigma_{z}\right)$. В области

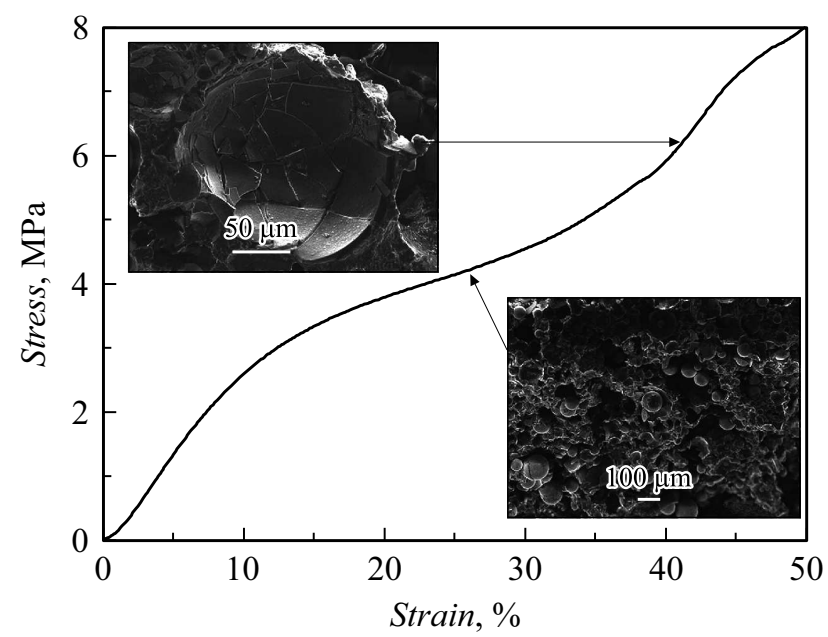

Рис. 1. Диаграмма деформирования пластины при статическом сжатии на установке Instron 5565. На вставках микрофотографии разломов сферопластика в средней части пластины при указанной стрелкой степени сжатия. 


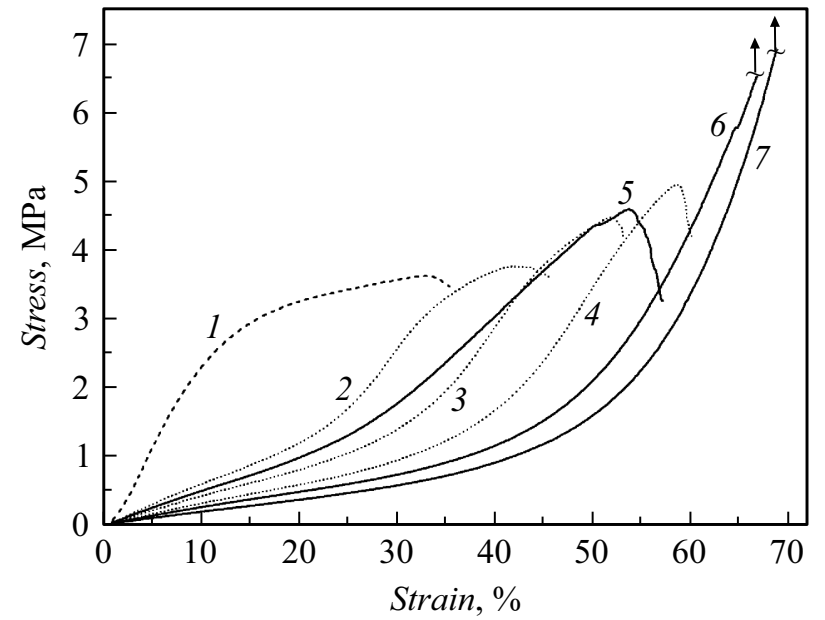

Рис. 2. Диаграммы сжатия цилиндрических образцов сферопластика при сжатии на установке Instron 5565 (1-4) и ударном деформировании на копре $(5-7): 1-$ исходный образец, 2 - после предварительного сжатия пластины сферопластика на $30 \%, 3-$ на $40 \%, 4-$ на $50 \%, 5-$ после ударного нагружения в режиме I (опыт № 1), 6, 7 - после ударного нагружения в режиме II (опыты № 2,3) (см. таблицу).

$\varepsilon_{z} \sim 14 \%$ наблюдается изгиб диаграммы деформирования и реализация более слабой зависимости напряжения от деформации, т.е. достигается предел „текучести“ сферопластика. На микрофотографиях разломов сферопластика обнаружено появление поврежденных стеклосфер. При дальнейшем сжатии сферопластика (при осевой деформации $\varepsilon_{z} \sim 34 \%$ ) наблюдается упрочнение и возрастание напряжения при деформировании до уровня, близкого к начальному участку кривой сжатия пластины сферопластика. На микрофотографиях видно, что разрушение стеклосфер происходит с образованием множества осколков (рис. 1). Такой характер разрушения стеклянных микросфер связывают с одновременным воздействием как осевой силы, так и вращения фрагментов микросферы из-за образования сдвиговых напряжений [18]. После нагружения пластины практически полностью восстанавливали свою первоначальную форму, что показывает малую остаточную деформацию, несмотря на обнаруженное разрушение микросфер.

Формоизменение вырезанных из центральной части пластин цилиндрических образцов сферопластика при сжатии до разрушения происходит по классической схеме. Образец приобретает форму „бочки“ и трещина прорастает под углом $\sim 45^{\circ}$ к оси нагружения. По диаграммам сжатия цилиндрических образцов, представленных на рис. 2 (кривые 1-4), видно, что объемное деформирование пластин сферопластика вызывает его размягчение тем большее, чем выше уровень предварительной деформации (эффект Маллинза). При 26\% деформации пластины наблюдается снижение модуля упругости сферопластика почти в 5 раз, дальнейшее повышение степени сжатия до $\varepsilon_{z} \sim 50 \%$ слабо сказывается на изменении модуля упругости. Однако прочность подвергнутых статическому сжатию сферопластиков возрастает. Возможной причиной повышения прочности является появление отслоений и воздушной пористости в объеме сферопластика, что препятствует распространению трещин по образцу.

Частотные зависимости действительной части комплексной диэлектрической проницаемости и тангенса угла диэлектрических потерь для исходного сферопластика и подвергнутого сжатию на установке Instron 5585 представлены на рис. 3, кривые 1-3,6. Отметим, что в области частот от 1 до $5 \mathrm{MHz}$ результаты, полученные методами автобалансируемого моста и коаксиальной линии, хорошо согласуются между собой. Видно, что как в исходном, так и в подвергнутом сжатию до $50 \%$ образцах частотные зависимости $\varepsilon^{\prime}$ и $\operatorname{tg} \delta$ качественно одинаковы, и обнаруживают две области частотной дисперсии
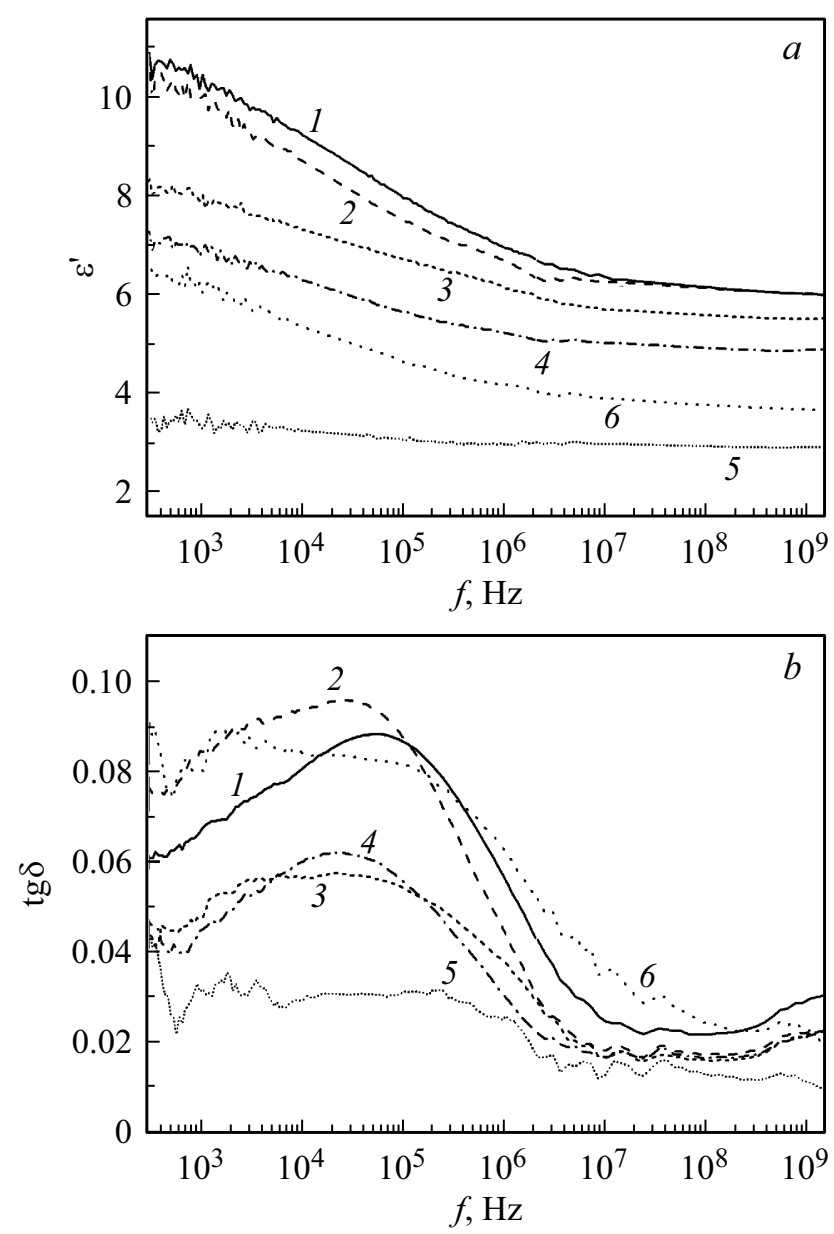

Рис. 3. Частотная зависимость относительной диэлектрической проницаемости $(a)$ и тангенса угла диэлектрических потерь $(b)$ сферопластика до деформирования (1), после сжатия на установке Instron $5565(2,3,6)$ и ударного сжатия на копре $(4,5): 1-$ исходный сферопластик, 2 - после деформирования на $30 \%, 3-$ на $40 \%, 4-$ после ударного нагружения на $\sim 42 \%$ в режиме I (опыт № 1 (см. таблицу)), 5 - после ударного нагружения на $83 \%$ в режиме II (опыт № 3 (см. таблицу)), 6 - после деформирования на 70\%. 
комплексной диэлектрической проницаемости. С увеличением частоты поля происходит снижение $\varepsilon^{\prime}$, a $\operatorname{tg} \delta$ достигает максимального значения при $f \approx 5 \cdot 10^{4} \mathrm{~Hz}$ и обнаруживает повышение с $f \sim 300 \mathrm{MHz}$. Сжатие пластины сферопластика до $\varepsilon_{z}=30 \%$ слабо сказывается на частотной зависимости $\varepsilon^{\prime}$, однако наблюдается некоторое смещение $\operatorname{tg} \delta$ в область более низких частот $\sim 1.6 \cdot 10^{4} \mathrm{~Hz}$. При сжатии до $40 \%$ (по сравнению с исходным образцом) наблюдается понижение $\varepsilon^{\prime}$, особенно заметное при частотах менее $10^{5} \mathrm{~Hz}$, и снижение значений тангенса угла диэлектрических потерь в $\sim 1.6$ раза в области частотной дисперсии.

Деформирование пластины до сжатия на 70\% вызывает снижение $\operatorname{tg} \delta$ в высокочастотной области $(f>300 \mathrm{MHz})$ и слабо сказывается на дисперсии в низкочастотной области. При этом повреждение пластин велико и не позволяет достоверно определять механические характеристики. Полученные микрофотографии разломов сферопластика обнаруживают практически полное разрушение микросфер.

То есть при нагрузке, вызывающей разрушение металлизированных микросфер, диэлектрические свойства изучаемого сферопластика улучшаются и наблюдается снижение частотной дисперсии комплексной диэлектрической проницаемости в области высоких частот более $300 \mathrm{MHz}$ при деформациях более 40\%.

\section{2. Ударное нагружение}

Рассмотрим теперь эксперименты по изучению изменения механических и диэлектрических свойств сферопластика после ударного нагружения на копре. В отличие от достаточно медленного сжатия на установке Instron 5585 при ударном сжатии происходит кратковременный разогрев объема образцов. Энергия ударника расходуется на разрушение металлизированных микросфер, неупругое деформирование образца и сжатие образующихся полостей.

В экспериментах на копре были реализованы два режима ударного нагружения пластин сферопластика с параметрами, представленными в таблице. В режиме I нагрузку выбирали таким образом, чтобы деформация пластины соответствовала уровню, достигнутому на установке Instron $\sim 40 \%$. В режиме II степень сжатия увеличивали в $\sim 2$ раза до уровня $70-80 \%$. Фотографии динамики удара в режиме II при подлете ударника, максимальном сжатии пластины сферопластика в момент остановки ударника и при отскоке ударника представлены на рис. 4. Видно, что при отскоке ударника пластина практически полностью восстановила свою форму в средней части, а трещины образовались по краям пластины. Отметим, что в режиме II интенсивность нагружения столь высока, что вызывает образование следов „побежалости“ на нагружаемой поверхности сферопластика, трещин по краям пластины и выброс „шлейфа“ пылевых продуктов разрушения (рис. 4,c).
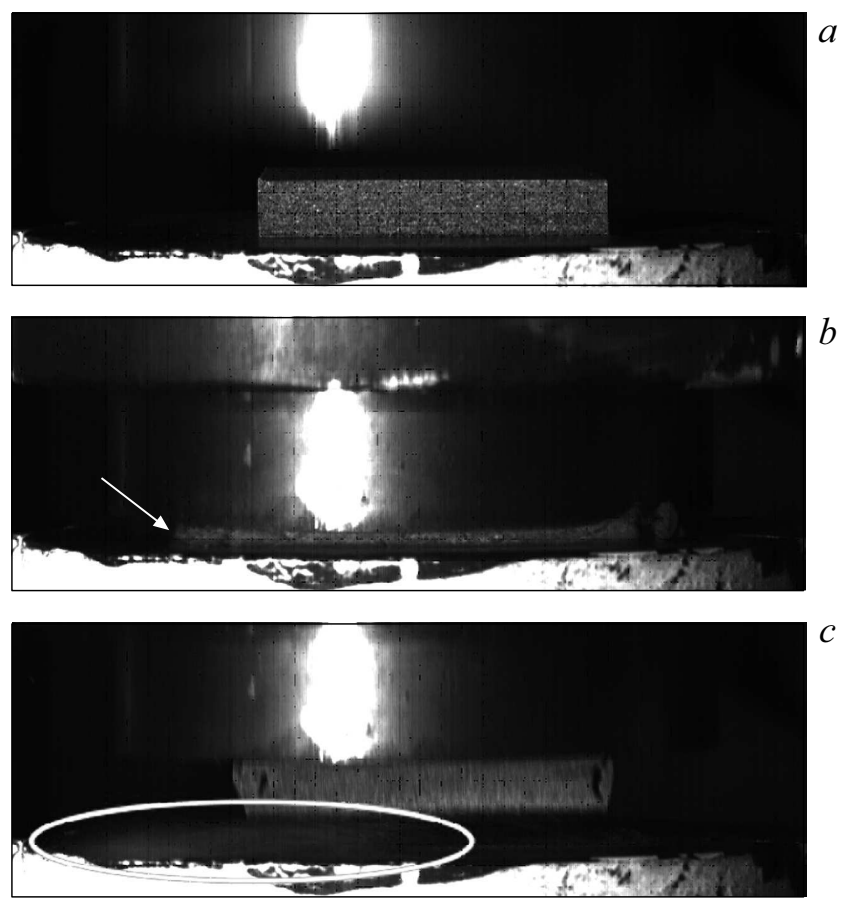

Pис. 4. Фотографии ударного нагружения пластины сферопластика на копре в момент подлета ударника $(a)$, при достижении наибольшей степени сжатия $(b)$ и отскока ударника с образцом от стола с образованием „шлейфа“ пылевых продуктов разрушения - выделено овалом (c). Опыт № 2, режим II (см. таблицу).

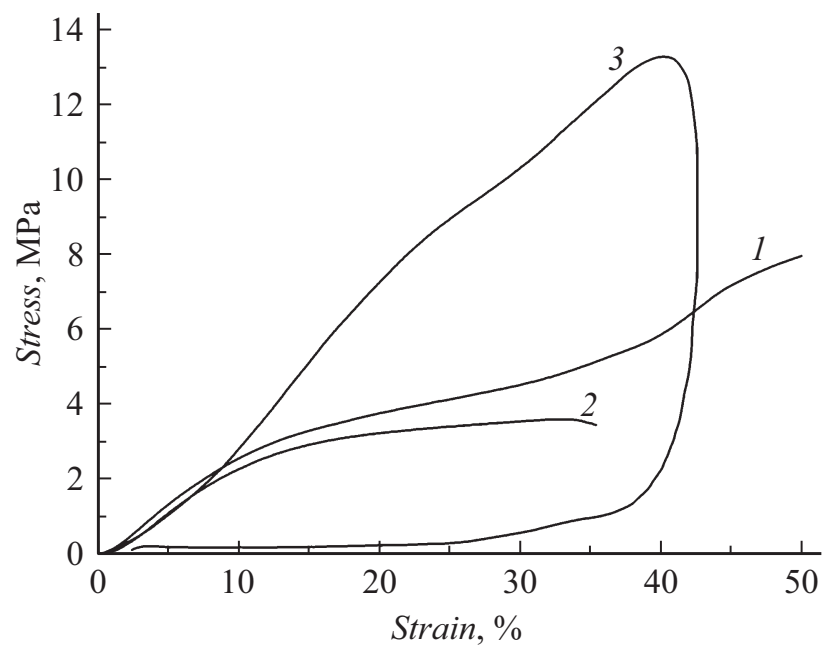

Pис. 5. Диаграммы деформирования при статическом сжатии исходной пластины (1) и исходного цилиндрического образца (2) на установке Instron 5585 и при ударном нагружении пластины до $42 \%$ на копре в режиме I (3).

Рассчитанные по методике [17] диаграммы напряжение-деформация при сжатии на копровой установке с использованием показаний тензодатчиков представлены на рис. 5 (кривая 3) в сравнении с экспериментами по статическому сжатию пластины (рис. 5, кривая 1) и 
Экспериментально реализованные параметры ударного нагружения пластин сферопластика

\begin{tabular}{l|c|c|c}
\hline \multicolumn{1}{c|}{ Режим ударного нагружения } & Режим I & \multicolumn{2}{|c}{ Режим II } \\
\hline \multicolumn{1}{c|}{ № опыта } & 1 & 2 & 3 \\
\hline Скорость груза (ударника), $\mathrm{m} / \mathrm{s}$ & 2.2 & 5.3 & 6.2 \\
Высота сброса груза, $\mathrm{m}$ & 0.250 & 1.408 & 1.932 \\
Время ударного нагружения, ms & 1.9 & 1.1 & 1.1 \\
Максимальное ускорение, $\mathrm{m} / \mathrm{s}^{2}$ & 1390 & 5368 & 5914 \\
Максимальная осевая деформация сжатия, \% & 42 & 72 & 83 \\
Энергия удара, J & 58.9 & 331.5 & 454.9
\end{tabular}

исходного цилиндрического образца (рис. 5, кривая 2). В режиме I сжатие пластины соответствует уровню, достигнутому на установке Instron 5585, и составляет 42\% от исходной толщины. Для режима II расчетная величина напряжения в средней части пластины достигает 45-49 МРа. Как видно из рис. 5, диаграммы сжатия при ударном и статическом нагружениях при одинаковой степени деформирования очень близки. Отметим, что более высокая степень сжатия в режиме II вызывает и большее снижение модуля упругости образцов, вырезанных после ударных испытаний из средней части пластин сферопластика, однако надежно регистрировать их прочность, также как и при сжатии на установке Instron 5585, затруднительно из-за сильного изменения их формы.

Консервативную оценку среднего повышения температуры $(\Delta T)$ при ударе можно получить, если считать, что вся потенциальная энергия ударника за вычетом энергии упругого деформирования пластины расходуется на повышение температуры пластины:

$$
\Delta T=\frac{m g H}{c \rho V}-\frac{E(\Delta l)^{2}}{2 c \rho},
$$

где $m$ - масса падающего груза, $g$ - ускорение свободного падения, $H$ - высота сброса груза, $E-$ модуль упругости образца, $\Delta l-$ абсолютное значение перемещения пластины до остановки ударника, $c$ удельная теплоемкость сферопластика, $\rho-$ плотность сферопластика, $V$ - объем пластины под ударником.

Так, для режима I оценка среднего повышения температуры объема пластины составляет $\Delta T \sim 3.7 \mathrm{~K}$, а для режима II и $H=1.93 \mathrm{~m}$ достигает $\Delta T=28.1 \mathrm{~K}$. Локальный же разогрев может быть значительно выше.

На микрофотографиях разломов сферопластика при сжатии на установке Instron на поверхности разрушенных микросфер с диаметром более $60 \mu \mathrm{m}$ обнаруживаются „бугристые“ структуры, напоминающие застывшие капли (рис. 6). При ударном сжатии на копре на поверхности разрушенных микросфер с диаметром более $60 \mu \mathrm{m}$ „бугристые“ структуры практически отсутствуют (рис. 7).

Изменение диэлектрических характеристик при ударном сжатии представлено на рис. 3, кривые 4,5. Видно, что различие в скорости деформирования (в течение

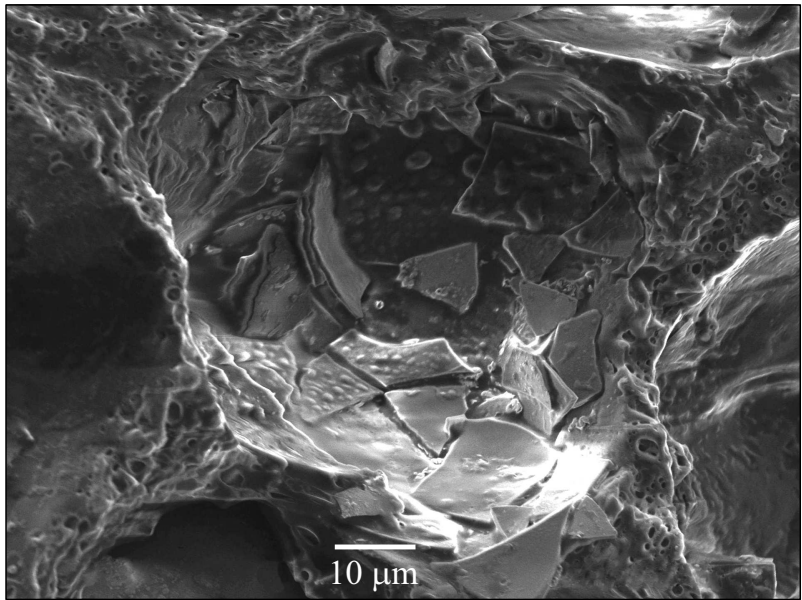

Рис. 6. Типовая микрофотография разрушения микросферы в объеме сферопластика после статического сжатия до $\varepsilon=50 \%$.

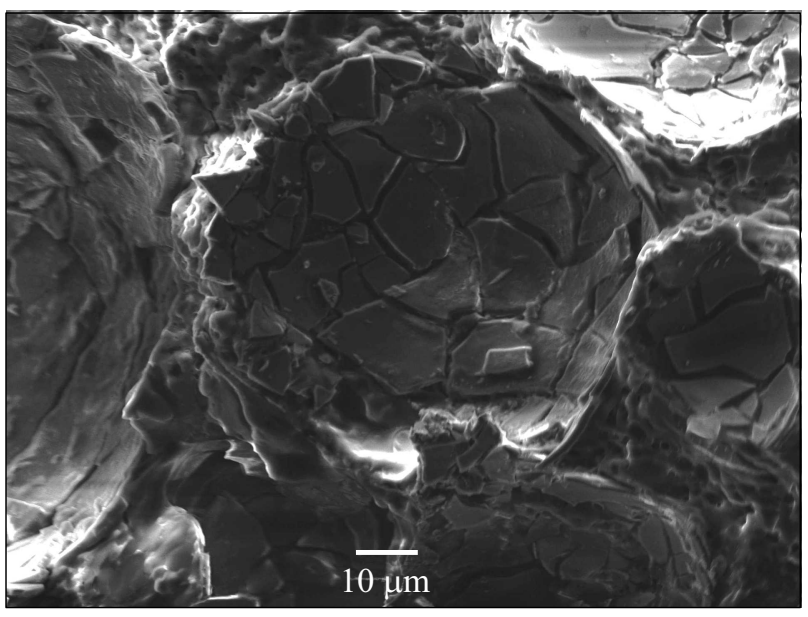

Рис. 7. Типовая микрофотография разрушения микросферы в объеме сферопластика после удара на копре (опыт № 2).

1 min на установке Instron 5585 или ударное нагружение за время действия $1.5 \mathrm{~ms}$ ) при одинаковых степенях сжатия сферопластика вызывает достаточно близкое изменение диэлектрических характеристик. Во всем частотном диапазоне наблюдается понижение $\varepsilon^{\prime}$ и $\operatorname{tg} \delta$. 
При интенсивном нагружении на ударном копре по режиму II $\varepsilon^{\prime}$ снижается более чем в 2 раза, а область частотной дисперсии практически исчезает.

\section{3. Обсуждение}

Рассматриваемый сферопластик содержит практически предельную степень наполнения металлизированными микросферами, позволяющую получать однородный образец. По результатам электронной микроскопии до механического нагружения максимальное расстояние между микросферами $\sim 45 \mu \mathrm{m}$ не превышает наибольшего радиуса микросферы, а среднее расстояние составляет $\sim 15 \mu \mathrm{m}$. При этом массовая доля вольфрама достаточно мала $\sim 9 \%$. Как известно, присутствие в диэлектрической системе металлических включений обусловлено высокой поляризуемостью частичек металла, а также их способностью образовывать электропроводящие кластеры $[19,20]$. Проведенные эксперименты показали, что образец является диэлектриком как до, так и после механических нагрузок и действительная часть комплексной электропроводности во всем изученном частотном диапазоне хорошо описывается линейной зависимостью от частоты электрического поля. Таким образом, порог перколяции как в исходном сферопластике, так и после механического нагружения не достигается.

Наличие металлических частиц создает в сферопластике область частотной дисперсии диэлектрической проницаемости, обусловленную Максвелл-Вагнеровской поляризацией. Учитывая отсутствие в изучаемом сферопластике эффекта перколяции между металлическими частицами, можно оценить время Максвелл-Вагнеровской поляризации по формуле $\tau \approx \varepsilon_{0} \varepsilon_{1}^{\prime} / \sigma_{2}$, где $\varepsilon_{1}^{\prime}$ - действительная часть относительной комплексной диэлектрической проницаемости, равная для полимерного связующего сферопластика $\sim 3.5$, а $\sigma_{2}$ - электропроводность металлического включения, для вольфрама $\sim 10^{7}(\Omega \cdot \mathrm{m})^{-1}$ при температуре $300 \mathrm{~K}[21]$. Оценка частоты максимума Максвелл-Вагнеровской поляризации дает величину $\sim 20 \mathrm{kHz}$, что достаточно близко к полученным экспериментально результатам $\sim 50 \mathrm{kHz}$ (для исходного сферопластика) и $\sim 17 \mathrm{kHz}$ (после механического нагружения). Это позволяет установить причину появления низкочастотной дисперсии диэлектрической проницаемости в изучаемом сферопластике.

Природа второй области дисперсии, наблюдаемой в области сверхвысоких частот, очевидно, связана с особенностями отражения, поглощения и рассеивания электромагнитной волны на металлизированных микросферах. При анализе диэлектрических характеристик сферопластика следует учитывать соотношения длины волны, диаметра микросфер, толщины скин-слоя металлизации поверхности микросфер и концентрации микросфер в сферопластике. Так, начало повышения $\operatorname{tg} \delta$ в области сверхвысоких частот происходит при $f>300 \mathrm{MHz}$, когда толщина скин-слоя вольфрама составляет $\sim 9 \mu \mathrm{m}$, что значительно меньше удвоенной толщины стенки вольфрамого покрытия микросфер ( $0.2 \mu \mathrm{m})$. С увеличением частоты до максимально реализованной в экспериментах $1.2 \mathrm{GHz}$ наблюдается дальнейшее повышение $\operatorname{tg} \delta$ и снижение толщины скин-слоя до $\sim 5 \mu \mathrm{m}$. Затухание электромагнитной волны в микрогетерогенном материале обусловлено наличием электрических, магнитных и омических потерь [22]. Сложная структура интерференции и дифракции при многократном рассеянии электромагнитной волны на неоднородностях и в пространстве между микросферами в гетерогенных средах может быть причиной появления максимума диэлектрических потерь в области частот выше $300 \mathrm{MHz}$, что и наблюдается в исходном сферопластике. Подобный эффект неоднократно отмечали в полимерных композитах, наполненных частицами металлов, ферромагнетиков и многослойных углеродных нанотрубок [23-25].

Анализ микрофотографий разломов сферопластика показал, что после механического нагружения, вызывающего разрушение металлизированных стеклосфер, появляется дополнительная воздушная пористость, которая снижает емкость сферопластика. Кроме того, из-за разрушения металлизированных сфер следует ожидать изменения многократного рассеяния электромагнитных волн и возрастание расстояния между осколками микросфер. Отметим, что Вольфрам относится к достаточно химически инертным металлам, он не реагирует с кислородом при температурах ниже $600^{\circ} \mathrm{C}$ [26], поэтому ожидать образования диэлектрических оксидов вольфрама в условиях экспериментов не приходится. Отметим, что при ударном нагружении в режиме II возможно некоторое снижение доли металла за счет его выброса из образца.

\section{Заключение}

Исследования диэлектрических свойств сферопластика с металлизированными вольфрамом стеклосферами в диапазоне частот от 300 до $1.2 \cdot 10^{9} \mathrm{~Hz}$ обнаружили существование двух областей дисперсии диэлектрической проницаемости. Низкочастотная дисперсия диэлектрической проницаемости характеризуется релаксационным процессом в области частот $\sim 50 \mathrm{kHz}$, и неплохо соответствует простой модели Максвелла-Вагнера. Высокочастотная область дисперсии начинает проявляться при частотах поля более $300 \mathrm{MHz}$ и связана со сложным характером интерференции и дифракции электромагнитной волны на металлизированных микросферах сферопластика.

Методами растровой электронной микроскопии показано, что статическое или ударное сжатие сферопластика при относительной деформации более 14 и 20\% соответственно сопровождается началом разрушения более крупных микросфер (>80 $\mu \mathrm{m})$. Вязкоупругие свойства полимерного связующего сферопластика позволяют достаточно быстро восстановить форму образца после 
деформирования практически без остаточных деформаций. Наиболее чувствительной к разрушению микросфер характеристикой является модуль упругости сферопластика. Заметное изменение комплексной диэлектрической проницаемости наблюдается при относительной деформации сжатия более 40\%. При сжатии $\sim 70 \%$ разрушение микросфер и образование дополнительной пористости сферопластика приводит к снижению относительной диэлектрической проницаемости во всем диапазоне частот, при этом практически исчезает высокочастотная дисперсия диэлектрической проницаемости.

\section{Конфликт интересов}

Авторы заявляют, что у них нет конфликта интересов.

\section{Список литературы}

[1] Берлин А.А., Шутов Ф.А. Упрочненные газонаполненные пластмассы. М.: Химия, 1980. 224 с.

[2] Тробимов А.Н., Зарубина А.Ю., СимоновЕмельянов И.Д. // Полимерные массы. 2014. № 11-12. C. 3-8.

[3] Гуртовник И.Г., Соколов В.И., Трофимов Н.Н., Шалгунов С.И. Радиопрозрачные изделия из стеклопластиков. М.: Мир, 2002. 368 c.

[4] Zhu B.L., Zheng H., Wang J., Ma J., Wu J., Wu R. // Composites. Part B. 2014. Vol. 58. P. 91-102.

[5] Мержсиевский Л.А., Реснянский А.Д. // Физика горения и взрыва. 1992. Т. 3. № 3. С. 119-121.

[6] Зубарева А.Н., Уткин А.В., Ефремов В.П. // Конструкции из композиционных материалов. 2016. № 3. С. 45-50.

[7] Gupta N., Priya S., Islam R., Ricci W. // Ferroelectrics. 2006. Vol. 345. P. 1-12.

[8] Димитриенко Ю.И., Сборщиков С.В., Соколов А.П., Гафаров Б.Р., Садовничий Д.Н. // Композиты и наноструктуры. 2013. № 3. С. 35-51.

[9] Байков А.В., Корохин Р.А., Солодилов В.И., Горенберг А.Я., Иванова-Мужжмиева В.Г., Зверева У.Г., Куперман A.M. // Композиты и наноструктуры. 2017. Т. 9. № 1. C. $1-11$.

[10] Singh A.K., Shishkin A., Koppel T., Gupta N. // Composites Part B. 2018. Vol. 149. P. 188-197.

[11] Meng X.-F., Shen X.-Q., Liu W. // Appl. Surf. Sci. 2012. Vol. 258. N 7. P. 2627-2631.

[12] Морохов И.Д., Петинов В.И., Трусов Л.И., Петрухин В.Ф. // УФН. 1981. Т. 133. Вып. 4. С. 653-692.

[13] Xu P., Han X., Wang C., Zhou D., Lu Z., Wen A., Wang X., Zhang B. // J. Phys. Chem. B. 2008. Vol. 112. P. 10443-10448.

[14] Сажсин Б.И., Лобанов А.М., Романовская О.С., Эйдельнант М.П., Койков С.Н., Шувалов В.П., Борисова М.Э. Электрические свойства полимеров. Л.: Химия, 1986.

[15] Impedance Spectroscopy / Ed. by E. Barsoukov, J. Ross Macdonald. Second edition. Hoboken, NJ: John Wiley \& Sons, 2005. $595 \mathrm{p}$.

[16] Милёхин Ю.М., Садовничий Д.Н., Шереметьев К.Ю., Калинин Ю.Г., Казаков Е.Д., Марков М.Б. // ДАН. 2019. Т. 487. № 2. С. 159-163. [Milekhin Yu.M., Sadovnichii D.N., Sheremetyev K.Yu., Kalinin Yu.G., Kazakov E.D., Markov M.B. // Doklady Chem. 2019. Vol. 487. N 1. P. 184-187.]
[17] Быков Д.Л., Коновалов Д.Н., Мельников В.П., Осавчук А.Н. // Известия РАН. Механика твердого тела. 2010. № 3. C. $143-154$.

[18] Gupta N., Woldesenbet E. // J. Cell. Plast. 2004. Vol. 40. P. 461-480.

[19] Снарский А.А., Безсуднов И.В., Севрюков В.А. Процессы переноса в макроскопически неупорядоченных системах: От теории среднего поля до перколяции. М.: ЛКИ, 2015. $299 \mathrm{c}$.

[20] Трофимов Н.Н., Канович М.З., Карташов Э.М., Натрусов В.И., Пономаренко А.Т., Шевченко В.Г., Соколов В.И., Симонов-Емельянов И.Д. Физика композиционных материалов. М.: Мир, 2005. 334 с.

[21] Abeles B., Pinch H.L., Gittleman J.I. // Phys. Rev. Lett. 1975. Vol. 35. N 4. P. 247-250.

[22] Сарычев А.К., Шалаев В.М. Электродинамика метаматериалов. М.: Научный мир, 2011. 224 с.

[23] Saini P., Choudhary V., Vijayan N., Kotnala R.K. // J. Phys. Chem. C. 2012. Vol. 116. N 13. P. 13403-13412.

[24] Pawar S.P., Gandi M., Saraf C., Bose S. // J. Mater. Chem. C. 2016. Vol. 4. N 22. P. 4954-4966.

[25] De Rosa I.M., Dinescu A., Sarasini F., Sarto M.S., Tamburrano A. // Compos. Sci. Technol. 2010. Vol. 70. N 1. P. $102-109$.

[26] Третьяков Ю.Д., Мартыненко Л.И., Григорьев А.Н., Цивадзе А.Ю. Неорганическая химия. Химия элементов. М.: МГУ, 2007. С. 307. 